\title{
Illustrating the importance of meta-analysing variances alongside means in ecology
} and evolution

\author{
Sánchez-Tójar, Alfredo; Moran, Nicholas P.; O'Dea, Rose E.; Reinhold, Klaus; Nakagawa, Shinichi
}

Published in:

Journal of Evolutionary Biology

Link to article, DOI:

10.1111/jeb.13661

Publication date:

2020

Document Version

Peer reviewed version

Link back to DTU Orbit

Citation (APA):

Sánchez-Tójar, A., Moran, N. P., O'Dea, R. E., Reinhold, K., \& Nakagawa, S. (2020). Illustrating the importance of meta-analysing variances alongside means in ecology and evolution. Journal of Evolutionary Biology, 33(9), 1216-1223. https://doi.org/10.1111/jeb.13661

\section{General rights}

Copyright and moral rights for the publications made accessible in the public portal are retained by the authors and/or other copyright owners and it is a condition of accessing publications that users recognise and abide by the legal requirements associated with these rights.

- Users may download and print one copy of any publication from the public portal for the purpose of private study or research.

- You may not further distribute the material or use it for any profit-making activity or commercial gain

- You may freely distribute the URL identifying the publication in the public portal 


\title{
Illustrating the importance of meta-analysing variances alongside means in ecology and evolution
}

\author{
Alfredo Sánchez-Tójar ${ }^{1}$, Nicholas P. Moran ${ }^{1,2}$, Rose E. O’Dea ${ }^{3}$, Klaus Reinhold ${ }^{1}$, Shinichi \\ Nakagawa $^{3}$
}

1. Department of Evolutionary Biology, Bielefeld University, Germany

2. Centre for Ocean Life DTU-Aqua, Technical University of Denmark, Lyngby, Denmark

3. Evolution \& Ecology Research Centre and School of Biological, Earth and

Environmental Sciences, University of New South Wales, Sydney, Australia

\section{Author for correspondence:}

Alfredo Sánchez-Tójar

Universität Bielefeld

Abteilung Evolutionsbiologie

Morgenbreede 45

33615 Bielefeld

Phone: +49 (0)521-106 2727

Fax: +495211062998

Email: alfredo.tojar@gmail.com

ORCIDs and email addresses:

Alfredo Sánchez-Tójar: 0000-0002-2886-0649; alfredo.tojar@gmail.com

Nicholas P. Moran: 0000-0002-7331-0400; nicholaspatrickmoran@gmail.com

Rose O'Dea: 0000-0001-8177-5075; rose.eleanor.o.dea@gmail.com

Klaus Reinhold: 0000-0002-0249-8346; klaus.reinhold@uni-bielefeld.de

Shinichi Nakagawa: 0000-0002-7765-5182; s.nakagawa@unsw.edu.au

Article type: Research article

Short running title: Meta-analysis of variance in biology

This article has been accepted for publication and undergone full peer review but has not been through the copyediting, typesetting, pagination and proofreading process, which may lead to differences between this version and the Version of Record. Please cite this article as doi: $\underline{10.1111 / J E B .13661}$

This article is protected by copyright. All rights reserved 


\section{Authors' contributions}

AST: Conceptualization, Data curation, Formal analysis, Investigation, Methodology, Project administration, Resources, Software, Validation, Visualization, Writing - original draft, Writing - review \& editing. NPM: Investigation, Methodology, Validation, Writing review \& editing. REO: Conceptualization, Methodology, Writing - review \& editing. KR: Funding acquisition, Supervision, Writing - review \& editing. SN: Conceptualization, Methodology, Funding acquisition, Supervision, Writing - review \& editing. 
DR ALFREDO SÁNCHEZ-TÓJAR (Orcid ID : 0000-0002-2886-0649)

MR. NICHOLAS PATRICK MORAN (Orcid ID : 0000-0002-7331-0400)

Article type : Research Papers

\title{
Illustrating the importance of meta-analysing variances alongside means in ecology and evolution
}

\begin{abstract}
Meta-analysis is increasingly used in biology to both quantitatively summarize available evidence for specific questions, and generate new hypotheses. While this powerful tool has mostly been deployed to study mean effects, there is untapped potential to study effects on (trait) variance. Here, we use a recently published dataset as a case study to demonstrate how meta-analysis of variance can be used to provide insights into biological processes. This dataset included 704 effect sizes from 89 studies, covering 56 animal species, and was originally used to test developmental stress effects on a range of traits. We found that developmental stress not only negatively affects mean trait values, but also increases trait variance, mostly in reproduction, showcasing how meta-analysis of variance can reveal previously overlooked effects. Furthermore, we show how meta-analysis of variance can be used as a tool to help meta-analysts make informed methodological decisions, even when the primary focus is on mean effects. We provide all data and comprehensive $\mathrm{R}$ scripts with detailed explanations to make it easier for researchers to conduct this type of analysis. We encourage meta-analysts in all disciplines to move beyond the world of means and start unravelling secrets of the world of variance.
\end{abstract}

Keywords: variability, variance ratio, coefficient of variation, early-life effects, opportunity for selection, parental effects 


\section{Introduction}

"Our preoccupation with averages has blinded us to biological realities" (Hogben and Sim, 1953). Despite the exponential increase in the use of meta-analysis in recent years (Gurevitch et al., 2018; Stewart, 2009) almost all meta-analyses have exclusively focused on the study of mean effects (using effect sizes such as response ratios and standardized mean differences between two groups; Koricheva and Gurevitch, 2014; Nakagawa and Santos, 2012). Meta-analysis is a powerful statistical tool for integrating and quantitatively summarizing findings (i.e. effect sizes) from multiple studies tackling a common research question, and for generating new hypotheses. Yet meta-analysts may be neglecting important biological realities by focusing on means alone.

In biological systems, variation from the mean is important to ecological and evolutionary processes. Phenotypic variance is important for how we understand and predict responses to selection using quantitative genetics because phenotypic variance is a key component of heritability and thus, of the breeder's equation (Arnold, 1992; Blows and Hoffmann, 2005; Walsh and Lynch, 2018). As such, phenotypic variance has been the focus of abundant research in biology, leading to the development of important evolutionary hypotheses (e.g. sex-chromosome hypothesis: James, 1973; reviewed in Reinhold and Engqvist, 2013), principles (Bateman's principles: Arnold, 1994; Bateman, 1948; reviewed in Janicke et al., 2016) and entire research fields (e.g. animal personality: reviewed in Réale et al., 2010, 2007).

Meta-analysis of variance components such as repeatability and heritability has been possible for a long time, and a few studies have done so (repeatability: Bell et al., 2009; Holtmann et al., 2017; heritability: Dochtermann et al., 2019). However, only recent statistical advances in meta-analysis have made it possible to analyse differences in variance between groups (Nakagawa et al., 2015), allowing us to test, for example, whether the opportunity of selection (variance in fitness) differs between groups. As a result, meta-analyses of variance are emerging (electronic supplementary material 1). For example, meta-analyses have shown that early-life dietary restriction not only affects mean longevity (English and Uller, 2016) but also increases variance in longevity (Senior et al., 2017); that poor condition increases 
mean risk-taking behaviour but does not generally affect total phenotypic variance (except in specific contexts; see Moran et al., 2020); and that sexual selection on males not only increases mean but also decreases variance in fitness-related traits (Cally et al., 2019). Despite this, meta-analyses of variance are still rarely used.

In this study, we aim to promote the use of meta-analysis of variance in biology and other disciplines. We used a recently published meta-analytic dataset of experimental studies (Eyck et al., 2019) as a case study to test the prediction that developmental stress not only negatively affects mean trait values, but also increases variance among individuals. Furthermore, we used meta-regression to test whether mean and variance effects differ across traits (e.g. behaviour, morphology, reproduction, etc.). Our meta-analysis of variance revealed developmental stress effects on variance, mostly on reproduction, and highlighted the importance of shifting some of our meta-analytic attention to the raw material for natural selection: variation.

\section{Methods}

Data analyzed

Experimental data on the effects of developmental stress on phenotype and fitness were obtained from Eyck et al. (2019). Before the analyses, we made modifications to the dataset (see details in electronic supplementary material 2).

\section{Effect size calculation}

We calculated two types of effect sizes and their associated sampling variances using the function 'escalc()' from the R package 'metafor' v.2.1-0 (Viechtbauer, 2010).

To study mean effects, we calculated the log response ratio (InRR, Hedges et al., 1999; also known as the ratio of means or ROM, Friedrich et al., 2008). We chose InRR instead of the standardized mean difference Cohen's d (Cohen, 1988) as used in Eyck et al. (2019), because: (i) InRR is less affected by heteroscedasticity (see results); and (ii) InRR can be both readily interpreted as the percentage of change between the two groups. Nonetheless, for comparison with the original study, we conducted an additional meta-analysis of means based on a standardized mean difference effect size (see electronic supplementary material 3 ). 
To study variance effects we calculated the log coefficient of variation ratio (InCVR; Nakagawa et al., 2015; updated in Senior et al., 2020). We chose InCVR over the variability ratio (InVR; Nakagawa et al., 2015; Senior et al., 2020) because groups can simultaneously differ at both the mean and variance levels (mean-variance relationship, e.g. Taylor's Law; Cohen and Xu, 2015; Nakagawa and Schielzeth, 2012), such as that observed in our sample (see electronic supplementary material 4), and InCVR is designed to account for that. An alternative approach to account for mean-variance relationships would be to model group means and standard deviations (SD) using univariate random slope mixed-effects models or bivariate mixed-effects meta-analytic models (also called arm-based models). Compared to InCVR, the latter approaches can have both advantages (e.g. incorporating interval scale data), and disadvantages (e.g. unknown sampling error covariances and complexity; Dias and Ades, 2016; Nakagawa et al., 2015). While we note that such approaches are possible, and have been successfully implemented elsewhere (O'Dea et al., 2019; Simons, 2015), our choice of InCVR was mostly driven by its simplicity and integration within established meta-analytic paradigms, and because InCVR is easily comparable to InRR.

Multiple treatment groups shared a common control group in 23 studies $(25.8 \%$ of all studies) involving 252 effect sizes ( $35.8 \%$ of all effect sizes), leading to nonindependence among effect sizes (Lajeunesse, 2011). To deal with this nonindependence, we adjusted the sample size of the control groups to be equal to the original sample size of that control group divided by the number of times that control group was compared to a treatment group (Noble et al., 2017). For the meta-analysis of means, all the revised effect sizes that we calculated were coded such that negative values indicate that developmental stress negatively affects fitness. That is, effect sizes were coded based on the expected relationship between the trait and fitness. For example, since fitness is expected to positively associate with body mass and immune response, no change in sign had to be implemented for those effect sizes. However, since fitness is expected to negatively associate with latency to reproduce and corticosterone levels, we inverted the sign of those effect sizes before the analyses (all decisions are available in data accessibility section). For the meta- 
analysis of variance, effect sizes were left unchanged as we expected an increase in variance across traits.

\section{Meta-analyses and meta-regressions}

We ran two multilevel meta-analytic (i.e. intercept-only) models, one for each type of effect size, to test whether developmental stress generally affects phenotype and fitness both at the mean ( $\mathrm{nRR}$ ) and variance (InCVR) levels, and two multilevel meta-regression models to test whether developmental stress effects differed across different types of traits. For meta-analytic models we investigated unexplained variation across studies (after accounting for sampling variance) by estimating total and separate relative heterogeneity for each random effect $(R$; Nakagawa and Santos, 2012; more in R script: 009_results_figures_and_tables.R), and absolute heterogeneity $(Q)$ using the R package 'metafor' v.2.1-0 (Viechtbauer, 2010). For meta-regressions, we estimated the percentage of variance explained by the

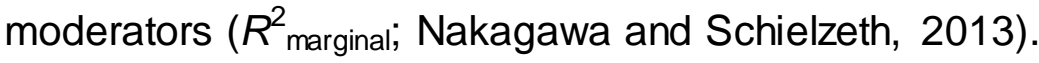

\section{Publication bias}

We assessed publication bias - specifically small-study bias - by running a variant of Egger's regression that uses the meta-analytic residuals as the response variable, and the precision (i.e. the square root of the inverse of the sampling variance) as the moderator (Nakagawa and Santos, 2012). Publication bias occurs when specific effect sizes are overrepresented in the literature, and it is normally indicated by an overrepresentation of large effect sizes of small precision (small-study bias; Jennions et al., 2013; Rothstein et al., 2005). Additionally, we assessed potential temporal trends in effect sizes that could indicate a time-lag bias or decline effect by running a multilevel meta-regression that included year of publication as a z-transformed moderator (Nakagawa and Santos, 2012; Sánchez-Tójar et al., 2018). A decline effect consists of decreasing support for a specific research hypothesis over time as evidence accumulates, and is normally identified by effect sizes becoming smaller over time (Jennions and Møller, 2002; Koricheva and Kulinskaya, 2019).

\section{Random effects}

All models included the following random effects: (i) observation ID, which represents the observational or residual variance that needs to be explicitly modelled 
in a meta-analytic model, (ii) study ID, which encompassed those estimates obtained within each specific study, (iii) species ID, which encompassed those estimates obtained for each species, and (iv) phylogeny, which consisted of a phylogenetic relatedness correlation matrix. To build the phylogeny, we searched for our species in the Open Tree Taxonomy (Rees and Cranston, 2017) and retrieved the phylogenetic relationships from the Open Tree of Life (Hinchliff et al., 2015) using the R package 'rotl' v.3.0.5 (Michonneau et al., 2016). We estimated branch lengths following Grafen (1989) as implemented in the function 'compute.brlen()' of the $R$ package 'ape' v.5.2 (Paradis and Schliep, 2019). The single polytomy encountered was dealt with via randomization using the function 'multi2di()' from the R package 'ape' v.5.2 (Paradis and Schliep, 2019).

We used the R programming language v.3.5.1 (R Core Team, 2018) throughout. All analyses were run in a Bayesian framework based on Stan programming language using the R package 'brms' v.2.9.0 (Bürkner, 2017; model parameters and convergence tests are available in the $\mathrm{R}$ code provided). Figures and tables were created using the R packages 'ggplot2' v.3.1.0 (Wickham, 2016), and 'gt' v.0.1.0 (lannone et al., 2019), respectively. All data and code are available from the data accessibility section.

\section{Results}

Our final dataset consisted of 704 effect sizes from 89 studies covering 56 animal species (Aves $=12 \mathrm{sp}$., Reptiles $=12 \mathrm{sp}$. , Arthropods $=11 \mathrm{sp}$. , Fishes $=9 \mathrm{sp}$., Amphibians $=6 \mathrm{sp}$., Mammals $=6 \mathrm{sp}$.; Figure S2).

\section{Meta-analysis of variance}

Overall, developmental stress increased variance by around $4 \%$ on average, albeit uncertainty was high (Table 1, Figure 1). The effect of developmental stress on variance differed depending on the trait studied, with reproduction showing the largest increase in variance (ca. 21\% on average) (Figure 2). However, the percentage of variance explained by the trait moderator was less than $1 \%$ (Table 2), indicating that most heterogeneity remained unexplained. 
Table 1. Results of the meta-analyses testing the effect of developmental stress on mean (InRR) and variance (InCVR) in phenotype and fitness. The results of the Egger's regression tests are also shown.

\begin{tabular}{|c|c|c|c|c|c|c|c|c|c|}
\hline $\begin{array}{l}\text { Effect } \\
\text { size }\end{array}$ & $\mathbf{k}$ & $\begin{array}{l}\text { Meta- } \\
\text { analytic } \\
\text { mean }\end{array}$ & $\begin{array}{c}I^{2} \text { obser. } \\
(\%)\end{array}$ & $\begin{array}{c}I^{2} \text { Study } \\
(\%)\end{array}$ & $\begin{array}{c}I^{2} \text { Species } \\
(\%)\end{array}$ & $\begin{array}{c}I_{\text {Phylo }}^{2} \\
\text { (\%) }\end{array}$ & $\begin{array}{c}R^{2} \text { Total } \\
(\%)\end{array}$ & $Q_{\text {test }}$ & $\begin{array}{l}\text { Egger's } \\
\text { test }\end{array}$ \\
\hline $\ln R R$ & 677 & $\begin{array}{r}-0.12 \\
{[-0.26,0.02]}\end{array}$ & $\begin{array}{r}36.7 \\
{[25.1,45.2]}\end{array}$ & $\begin{array}{r}32.5 \\
{[18.5,43.4]}\end{array}$ & $\begin{array}{r}12.2 \\
{[0.0,25.5]}\end{array}$ & $\begin{array}{r}19.4 \\
{[0.7,38.9]}\end{array}$ & $\begin{array}{r}99.9 \\
{[99.9,100.0]}\end{array}$ & 14993 & $\begin{array}{r}-0.13 \\
{[-0.18,-0.06]}\end{array}$ \\
\hline InCVR & 701 & $\begin{array}{r}0.04 \\
{[-0.08,0.14]}\end{array}$ & $\begin{array}{r}45.9 \\
{[35.6,55.7]}\end{array}$ & $\begin{array}{r}21.5 \\
{[7.6,31.2]}\end{array}$ & $\begin{array}{r}19.3 \\
{[4.4,28.3]}\end{array}$ & $\begin{array}{r}4.1 \\
{[0.0,25.7]}\end{array}$ & $\begin{array}{r}91.7 \\
{[90.2,93.5]}\end{array}$ & 1963 & $\begin{array}{r}0.33 \\
{[0.16,0.49]}\end{array}$ \\
\hline
\end{tabular}

$\mathrm{k}=$ number of estimates; $I^{2}=$ heterogeneity; $Q_{\text {test }}=$ Cochrane's $Q$ test; $N A=$ not applicable; Obser. = Observational or residual variance; Phylo $=$ Phylogeny. Egger's test $=$ intercept of an Egger's regression following Nakagawa and Santos (2012). Estimates shown correspond to modes and 95\% Highest Posterior Density Intervals. N = 89 studies.

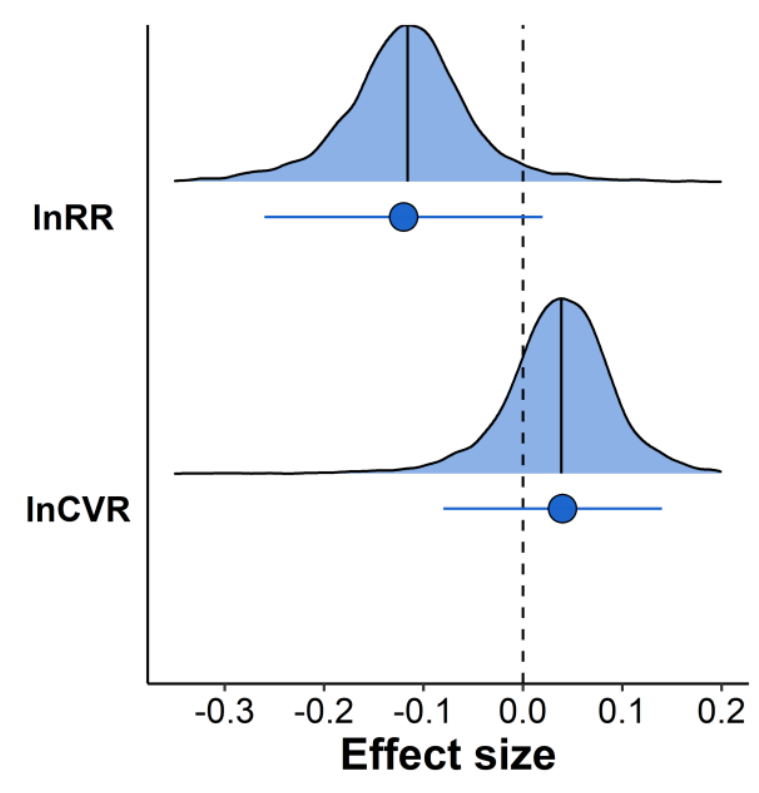

Figure 1. Developmental stress affects negatively the mean, and slightly increases variance in trait values. Points and associated error bars correspond to posterior modes and $95 \%$ highest posterior density intervals (HPDI) from the meta-analyses. The posterior distributions with vertical lines indicating the median are plotted on top of their respective modes and 95\% $\mathrm{HPDI}$. 


\section{Meta-analysis of mean}

Our results showed that, on average, developmental stress negatively affected mean trait values by around 13\% (Table 1, Figure 1). The meta-regression showed that developmental stress negatively affected all traits, with the strongest effects being on reproduction (ca. $21 \%$ on average) and behaviour (ca. $16 \%$ on average; Table 2 , Figure 2). Nonetheless, heterogeneity remained high even after including the trait moderator (Table 2). Our additional meta-analysis based on a standardized mean difference effect size led to a meta-analytic mean that was very similar to the original study (i.e. Eyck et al. 2019; see electronic supplementary material 3). However, our phylogenetically corrected meta-analytic mean was much more uncertain (i.e. wider credible intervals overlapping zero). Additionally, relative $(F)$ and mostly absolute $(Q)$ heterogeneity were lower, indicating lower unexplained variation across studies in our meta-analysis (see electronic supplementary material 3 ).

Table 2. Results of the meta-regressions testing whether the effect of developmental stress on mean (InRR) and variance (InCVR) differ across traits. The results of the meta-regressions assessing temporal trends in effect sizes are also shown. 


\begin{tabular}{|c|c|c|c|}
\hline Estimates & Mode [95\% HPDI] & $\mathbf{N}$ & $\mathbf{k}$ \\
\hline \multicolumn{4}{|l|}{$\operatorname{lnRR}(k=677)$} \\
\hline Behaviour & $-0.16[-0.30,-0.01]$ & 33 & 95 \\
\hline Development & $-0.13[-0.29,0.01]$ & 17 & 55 \\
\hline Metabolism and Physiology & $-0.12[-0.27,0.02]$ & 26 & 118 \\
\hline Morphology & $-0.09[-0.22,0.06]$ & 51 & 308 \\
\hline Reproduction & $-0.18[-0.34,-0.04]$ & 14 & 62 \\
\hline Survival & $-0.10[-0.28,0.10]$ & 7 & 39 \\
\hline$R^{2}$ marginal $(\%)=$ & $0.58[0.07,1.50]$ & - & - \\
\hline \multicolumn{4}{|c|}{ InRR ( $k=677$; time-lag bias test) } \\
\hline Intercept & $-0.12[-0.25,0.01]$ & - & - \\
\hline Year of publication & $0.01[-0.02,0.06]$ & - & - \\
\hline$R^{2}$ marginal $(\%)=$ & $0.00[0.00,0.51]$ & - & - \\
\hline \multicolumn{4}{|l|}{$\operatorname{lnCVR}(k=701)$} \\
\hline Behaviour & $0.03[-0.15,0.17]$ & 33 & 100 \\
\hline Development & $-0.01[-0.19,0.15]$ & 17 & 55 \\
\hline Metabolism and Physiology & $0.03[-0.11,0.20]$ & 26 & 122 \\
\hline Morphology & $0.03[-0.11,0.14]$ & 51 & 325 \\
\hline Reproduction & $0.18[0.01,0.36]$ & 14 & 60 \\
\hline Survival & $0.10[-0.18,0.34]$ & 7 & 39 \\
\hline$R^{2}$ marginal $(\%)=$ & $0.72[0.05,2.63]$ & - & - \\
\hline \multicolumn{4}{|c|}{$\operatorname{lnCVR}(\mathrm{k}=701$; time-lag bias test $)$} \\
\hline Intercept & $0.05[-0.07,0.16]$ & - & - \\
\hline Year of publication & $-0.03[-0.09,0.02]$ & - & - \\
\hline$R^{2}$ marginal $(\%)=$ & $0.01[0.00,1.19]$ & - & - \\
\hline
\end{tabular}

$\mathrm{N}=$ number of studies; $\mathrm{k}=$ number of estimates; $R^{2}$ marginal = percentage of variance explained by the moderators (Nakagawa and Schielzeth 2013). Year of publication was z-transformed. Estimates shown correspond to posterior modes and $95 \%$ Highest Posterior Density Intervals (HPDI). 


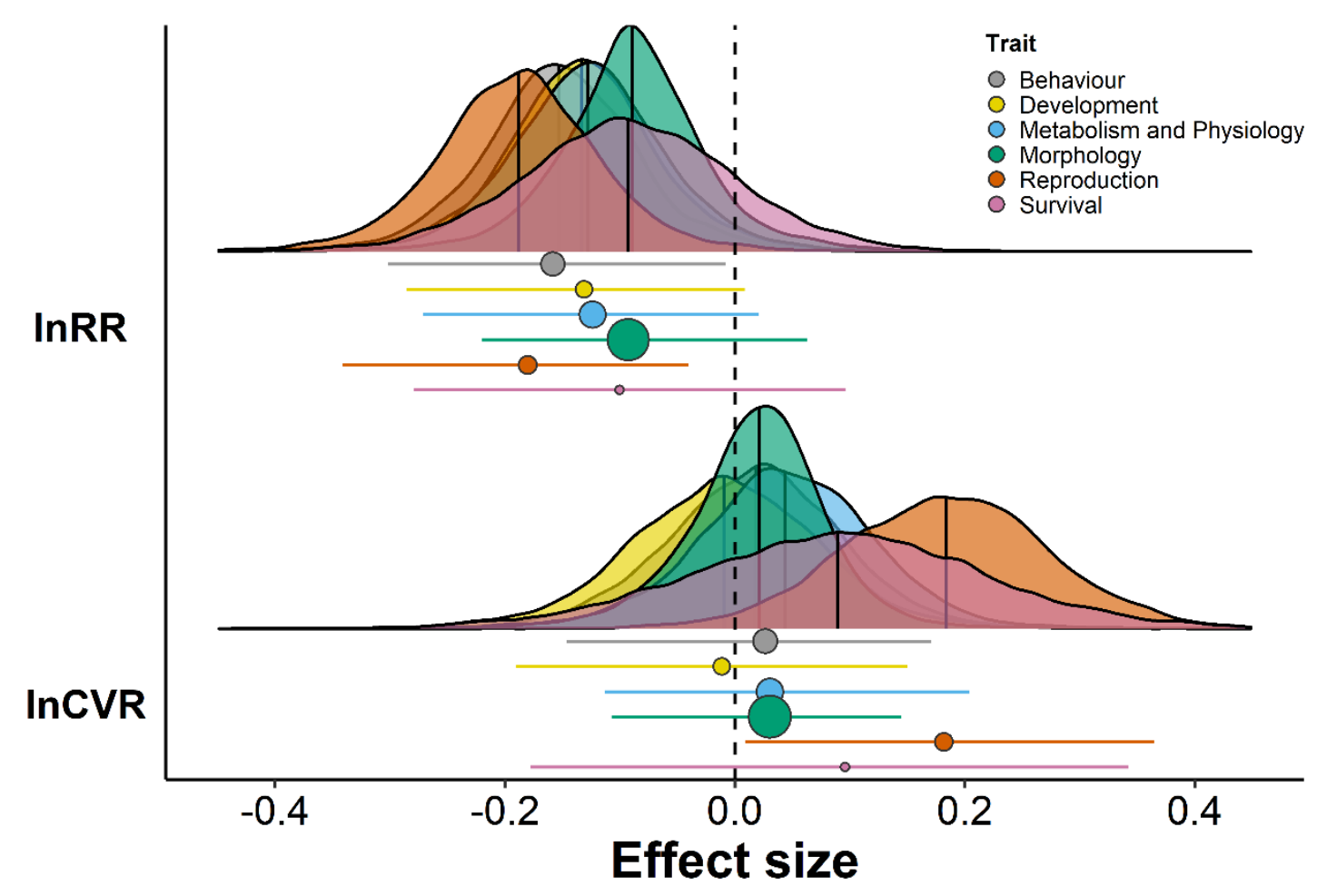

Figure 2. Developmental stress affects mean and variance differently across traits, with the strongest effects being on reproduction. Points and associated error bars correspond to posterior modes and 95\% highest posterior density intervals (HPDI) from the meta-regressions. The posterior distributions with vertical lines indicating the median are plotted on top of their respective modes and 95\% HPDI. Point size is proportional to the number of effect sizes (see Table 2).

\section{Publication bias}

The intercepts of the Egger's regressions were clearly different from zero, suggesting the existence of publication bias (small-study bias) at both mean and variance levels (Table 1). The meta-regressions testing for temporal trends in effect sizes showed a small effect size reduction over time at both mean and variance levels, but the trends were uncertain and the percentage of variance explained by the moderator was essentially zero (Table 2).

\section{Discussion}

Combining a recent advance in meta-analytic methodology and a case study, we demonstrate how meta-analysis of variance can shed light on important biological processes. We showed that developmental stress not only negatively affects mean trait values, but can also increase trait variance among individuals. Our results have 
also revealed that developmental stress affects reproduction most strongly, both at the mean and at the variance level. Overall, we encourage meta-analysts to focus on both mean and variance effects to unearth previously overlooked effects.

\section{Case study: developmental stress effects}

Developmental stress effects on phenotype and fitness have been studied often. For example, studies have investigated the effects of different developmental stressors on morphology and coloration (Tschirren et al., 2009), attractiveness (Kahn et al., 2012), social network position (Boogert et al., 2014), telomere dynamics (Grunst et al., 2019), and fitness (Arbuthnott and Whitlock, 2018). Several reviews and metaanalyses have attempted to synthesize how different developmental stressors influence phenotype and fitness. However, the majority focused on mean effects (e.g. English and Uller, 2016; Eyck et al., 2019; Macartney et al., 2019; Nakagawa et al., 2012), with only a few recent meta-analyses exploring the effects of specific developmental stressors on variance. For example, O'Dea et al. (2019) showed that experimentally increasing developmental temperature leads to an $\sim 8 \%$ average increase in phenotypic variance across 43 fish species, which could facilitate adaptation to novel environments by increasing the amount of rare phenotypes in the population. Dietary restriction during development has also been shown to lead to an $\sim 9 \%$ average increase of variance in longevity across 14 animal species, which may affect the strength of selection on longevity (Senior et al., 2017). In contrast, lower quality/quantity diets during development have been shown to lead to an $\sim 8 \%$ average decrease of variance in risk-taking behaviour across animal species, suggesting that individuals may converge on high-risk behavioural phenotype under developmental diet stress (Moran et al. 2020). In all, these recent meta-analyses of variance provide good evidence suggesting that developmental stress can affect phenotypic variance and the opportunity for selection.

Our results first confirm that overall, developmental stress negatively affects mean trait values, with the strongest effects on reproduction (ca. 21\%) and behaviour (ca. $16 \%)$. Furthermore, our meta-analysis of variance revealed that even when multiple developmental stressors are considered together (e.g. physiological, environmental, nutritional, etc) - as in our study, developmental stress also leads to a small increase of around $4 \%$ on average in trait variance, with that effect being mostly driven by an 
increase in variance of around $21 \%$ on average in reproduction. Thus, the increase in variance observed in experimental versus control treatments is in agreement with the recent meta-analyses above (Senior et al., 2017; O'Dea et al., 2019).

Furthermore, our results seem in agreement with another two recent meta-analyses of variance showing that environmental stress (i.e. not only during development) measured as single-food diets and high temperature increase variance in fitness (Senior et al., 2015) and reproductive success (García-Roa et al., 2018), respectively. Our results on variance in reproduction, specifically, confirm previous theoretical predictions (Martin and Lenormand, 2006) and recent experimental work (Martinossi- Allibert et al., 2017). Since a recent meta-analysis showed that environmental stress can increase both genetic and residual variances (i.e. not just total phenotypic variance; Rowiński and Rogell, 2017), developmental stress could have far reaching evolutionary consequences. Overall, our study shows that developmental stress may lead to increased opportunity for selection, however, these results should be interpreted carefully as most of the heterogeneity in our models remained unexplained.

\section{Promoting meta-analysis of variance}

Our results show how meta-analysing variances alongside means can unearth otherwise overlooked effects and contribute to our understanding of biological processes. Indeed, all but one (93\%) of the meta-analyses of variance performed in the field of ecology and evolution (see electronic supplementary material 1) revealed important variance effects that otherwise would have remained unknown.

Calculating InCVR for a meta-analysis of variance requires essentially the same information needed to estimate commonly used effect size statistics for comparing means such as Hedges' $g$ (Hedges, 1981) and InRR (Hedges et al., 1999). Specifically, one simply needs the mean, SD and sample size for the two groups being compared (Nakagawa et al., 2015). Since over $60 \%$ of published metaanalyses in ecology and evolution compare means (Koricheva and Gurevitch, 2014; Nakagawa and Santos, 2012), meta-analysis of variance could be applied to most meta-analytic datasets in the field, even retrospectively. 
Nonetheless, there are some limitations that meta-analysts need to know when conducting a meta-analysis of variance. First, as in the case of InRR, only ratio scale data can be used to calculate InCVR, and equations to derive InCVR from other statistics such as $F$ or $t$ statistics are not available. Furthermore, InCVR cannot be calculated for group-level proportional data (Nakagawa et al., 2015). Second, absolute error variance will generally be larger for InCVR than for mean-based effect size statistics. This large sampling variance will generally lead to lower levels of absolute heterogeneity in InCVR compared to mean-based effect size statistics (Table 1), and overall highlights that meta-analysing variances will usually be more data-hungry than meta-analysing means. Despite these limitations, meta-analysis of variance is rather uncomplicated, making it easy for meta-analysts to shift some of their preoccupations with averages to more variance-driven hypothesis testing and development.

Meta-analysis of variance not only can reveal important biological realities, but can also help with making informed methodological decisions. By identifying whether the compared groups show unequal variances (i.e. whether there is heteroscedasticity), meta-analysis of variance can help meta-analysts choose between effect sizes that assume homoscedasticity (e.g. Cohen's d, Cohen, 1988; Hedges' g, Hedges, 1981), and those that incorporate heteroscedasticity (e.g. standardized mean difference with heteroscedasticity or SMDH, Bonett, 2009, 2008; see electronic supplementary material 3). This is important because not accounting for heteroscedasticity can cause parameter misestimation in meta-analysis (Bonett, 2009, 2008). Overall, we suggest that even when variance-based hypotheses are of no interest to the researcher, meta-analysis of variance can still be used as a powerful methodological tool for helping to choose the most appropriate effect size statistic.

\section{Conclusion}

Our analyses on the effects of developmental stress on both mean and variance in phenotype and fitness showcases how meta-analysing variances alongside means can help unravel crucial processes. Importantly, meta-analysing variances is not limited to ecology and evolution, and can also advance disciplines such as agriculture (Knapp and Heijden, 2018), social sciences (O'Dea et al., 2018) and 
medicine (Senior et al., 2016). We have also shown how meta-analysis of variance can be used as a methodological tool to make informed decisions on how to choose effect size statistics for the study of mean effects. Overall, a holistic understanding of the world requires moving beyond the world of means to incorporate the world of variance.

\section{Competing interests}

We declare no competing interests.

\section{Acknowledgments}

We are grateful to the authors of the original publication for sharing data with us and answering our questions about the data, especially Harrison J.F. Eyck and Tim S. Jessop. We are grateful to Pietro D'Amelio for enlightening discussions about data visualization, and the reviewers and the editor for their helpful comments on the manuscript.

\section{Electronic Supplementary Material}

Electronic supplementary material file attached in $\mathrm{html}$ format, and also available at: https://asanchez-tojar.github.io/meta-analysis_of_variance/SupplementaryMaterial.

\section{Data accessibility}

All data and code are available at Zenodo (http://doi.org/10.5281/zenodo.3843018), and brms models are available as .RData at the Open Science Framework (https://doi.org/10.17605/OSF.IO/YJUA8).

\section{Funding}

This research was funded by the German Research Foundation (DFG) as part of the SFB TRR 212 (NC ${ }^{3}$ ) - Project numbers 316099922 and 396782608; and the Australian Research Discovery Grant, DP180100818. NPM was partially funded by the European Union's Horizon 2020 research and innovation programme under the Marie Sklodowska-Curie grant agreement No 836937.

\section{References}

Arbuthnott, D., Whitlock, M.C., 2018. Environmental stress does not increase the mean strength of selection. J. Evol. Biol. 31, 1599-1606. https://doi.org/10.1111/jeb.13351 
Arnold, S.J., 1994. Bateman's Principles and the Measurement of Sexual Selection in Plants and Animals. Am. Nat. 144, S126-S149. https://doi.org/10.1086/285656

Arnold, S.J., 1992. Constraints on Phenotypic Evolution. Am. Nat. 140, S85-S107. https://doi.org/10.1086/285398

Bateman, A.J., 1948. Intra-sexual selection in Drosophila. Heredity 2, 349-368. https://doi.org/10.1038/hdy.1948.21

Bell, A.M., Hankison, S.J., Laskowski, K.L., 2009. The repeatability of behaviour: a metaanalysis. Anim. Behav. 77, 771-783. https://doi.org/10.1016/j.anbehav.2008.12.022

Blows, M.W., Hoffmann, A.A., 2005. A Reassessment of Genetic Limits to Evolutionary Change. Ecology 86, 1371-1384. https://doi.org/10.1890/04-1209

Bonett, D.G., 2009. Meta-analytic interval estimation for standardized and unstandardized mean differences. Psychol. Methods 14, 225-238. https://doi.org/10.1037/a0016619

Bonett, D.G., 2008. Confidence intervals for standardized linear contrasts of means. Psychol. Methods 13, 99-109. https://doi.org/10.1037/1082-989X.13.2.99

Boogert, N.J., Farine, D.R., Spencer, K.A., 2014. Developmental stress predicts social network position. Biol. Lett. 10, 20140561. https://doi.org/10.1098/rsbl.2014.0561

Bürkner, P.-C., 2017. brms: An R Package for Bayesian Multilevel Models Using Stan. J. Stat. Softw. 80, 1-28. https://doi.org/10.18637/jss.v080.i01

Cally, J.G., Stuart-Fox, D., Holman, L., 2019. Meta-analytic evidence that sexual selection improves population fitness. Nat. Commun. 10, 2017. https://doi.org/10.1038/s41467019-10074-7

Cohen, J., 1988. Statistical power analysis for the behavioral sciences, 2nd ed. ed. L. Erlbaum Associates, Hillsdale, N.J.

Cohen, J.E., Xu, M., 2015. Random sampling of skewed distributions implies Taylor's power law of fluctuation scaling. Proc. Natl. Acad. Sci. 112, 7749-7754.

Dias, S., Ades, A.E., 2016. Absolute or relative effects? Arm-based synthesis of trial data. Res. Synth. Methods 7, 23-28. https://doi.org/10.1002/jrsm.1184

Dochtermann, N.A., Schwab, T., Anderson Berdal, M., Dalos, J., Royauté, R., 2019. The Heritability of Behavior: A Meta-analysis. J. Hered. 110, 403-410. https://doi.org/10.1093/jhered/esz023

English, S., Uller, T., 2016. Does early-life diet affect longevity? A meta-analysis across experimental studies. Biol. Lett. 12, 20160291. https://doi.org/10.1098/rsbl.2016.0291

Eyck, H.J.F., Buchanan, K.L., Crino, O.L., Jessop, T.S., 2019. Effects of developmental stress on animal phenotype and performance: a quantitative review. Biol. Rev. 94, 1143-1160. https://doi.org/10.1111/brv.12496

Friedrich, J.O., Adhikari, N.K., Beyene, J., 2008. The ratio of means method as an alternative to mean differences for analyzing continuous outcome variables in meta- 
analysis: A simulation study. BMC Med. Res. Methodol. 8, 32.

https://doi.org/10.1186/1471-2288-8-32

García-Roa, R., Garcia-Gonzalez, F., Noble, D.W.A., Carazo, P., 2018. Temperature as a modulator of sexual selection. EcoEvoRxiv. https://doi.org/10.32942/osf.io/hqvmd

Grafen, A., 1989. The phylogenetic regression. Philos. Trans. R. Soc. Lond. B Biol. Sci. 326, 119-157. https://doi.org/10.1098/rstb.1989.0106

Grunst, A.S., Grunst, M.L., Gonser, R.A., Tuttle, E.M., 2019. Developmental stress and telomere dynamics in a genetically polymorphic species. J. Evol. Biol. 32, 134-143. https://doi.org/10.1111/jeb.13400

Gurevitch, J., Koricheva, J., Nakagawa, S., Stewart, G., 2018. Meta-analysis and the science of research synthesis. Nature 555, 175-182. https://doi.org/10.1038/nature25753

Hedges, L.V., 1981. Distribution Theory for Glass's Estimator of Effect size and Related Estimators. J. Educ. Stat. 6, 107-128. https://doi.org/10.3102/10769986006002107 Hedges, L.V., Gurevitch, J., Curtis, P.S., 1999. The Meta-Analysis of Response Ratios in Experimental Ecology. Ecology 80, 1150-1156. https://doi.org/10.1890/00129658(1999)080[1150:TMAORR]2.0.CO;2

Hinchliff, C.E., Smith, S.A., Allman, J.F., Burleigh, J.G., Chaudhary, R., Coghill, L.M., Crandall, K.A., Deng, J., Drew, B.T., Gazis, R., Gude, K., Hibbett, D.S., Katz, L.A., Laughinghouse, H.D., McTavish, E.J., Midford, P.E., Owen, C.L., Ree, R.H., Rees, J.A., Soltis, D.E., Williams, T., Cranston, K.A., 2015. Synthesis of phylogeny and taxonomy into a comprehensive tree of life. Proc. Natl. Acad. Sci. 112, 12764-12769. https://doi.org/10.1073/pnas.1423041112

Hogben, L., Sim, M., 1953. The Self-Controlled and Self-Recorded Clinical Trial for LowGrade Morbidity. Br. J. Prev. Soc. Med. 7, 163-179.

Holtmann, B., Lagisz, M., Nakagawa, S., 2017. Metabolic rates, and not hormone levels, are a likely mediator of between-individual differences in behaviour: a meta-analysis. Funct. Ecol. 31, 685-696. https://doi.org/10.1111/1365-2435.12779

lannone, R., Cheng, J., Schloerke, B., 2019. gt: Easily Create Presentation-Ready Display Tables.

James, J.W., 1973. 353. Note: Covariances Between Relatives due to Sex-Linked Genes. Biometrics 29, 584-588. https://doi.org/10.2307/2529178

Janicke, T., Häderer, I.K., Lajeunesse, M.J., Anthes, N., 2016. Darwinian sex roles confirmed across the animal kingdom. Sci. Adv. 2, e1500983. https://doi.org/10.1126/sciadv.1500983 
Jennions, M., Lortie, C.J., Rosenberg, M.S., Rothstein, H., 2013. Publication and related biases, in: Handbook of Meta-Analysis in Ecology \& Evolution. Princeton University Press, Princeton, pp. 207-236.

Jennions, M.D., Møller, A.P., 2002. Relationships fade with time: a meta-analysis of temporal trends in publication in ecology and evolution. Proc. R. Soc. Lond. B Biol. Sci. 269, 43-48. https://doi.org/10.1098/rspb.2001.1832

Kahn, A.T., Livingston, J.D., Jennions, M.D., 2012. Do females preferentially associate with males given a better start in life? Biol. Lett. 8, 362-364. https://doi.org/10.1098/rsbl.2011.1106

Knapp, S., Heijden, M.G.A. van der, 2018. A global meta-analysis of yield stability in organic and conservation agriculture. Nat. Commun. 9, 1-9. https://doi.org/10.1038/s41467018-05956-1

Koricheva, J., Gurevitch, J., 2014. Uses and misuses of meta-analysis in plant ecology. J. Ecol. 102, 828-844. https://doi.org/10.1111/1365-2745.12224

Koricheva, J., Kulinskaya, E., 2019. Temporal Instability of Evidence Base: A Threat to Policy Making? Trends Ecol. Evol. 34, 895-902. https://doi.org/10.1016/j.tree.2019.05.006

Lajeunesse, M.J., 2011. On the meta-analysis of response ratios for studies with correlated and multi-group designs. Ecology 92, 2049-2055. https://doi.org/10.1890/11-0423.1

Macartney, E.L., Crean, A.J., Nakagawa, S., Bonduriansky, R., 2019. Effects of nutrient limitation on sperm and seminal fluid: a systematic review and meta-analysis. Biol. Rev. 94, 1722-1739. https://doi.org/10.1111/brv.12524

Martin, G., Lenormand, T., 2006. A General Multivariate Extension of Fisher's Geometrical Model and the Distribution of Mutation Fitness Effects Across Species. Evolution 60, 893-907. https://doi.org/10.1111/j.0014-3820.2006.tb01169.x

Martinossi-Allibert, I., Arnqvist, G., Berger, D., 2017. Sex-specific selection under environmental stress in seed beetles. J. Evol. Biol. 30, 161-173. https://doi.org/10.1111/jeb.12996

Michonneau, F., Brown, J.W., Winter, D.J., 2016. rotl: an R package to interact with the Open Tree of Life data. Methods Ecol. Evol. 7, 1476-1481. https://doi.org/10.1111/2041-210X.12593

Moran, N.P., Sánchez-Tójar, A., Schielzeth, H., Reinhold, K., 2020. Poor condition promotes high-risk behaviours but context-dependency is key: A systematic review and metaanalysis. https://doi.org/10.32942/osf.io/xsehd

Nakagawa, S., Lagisz, M., Hector, K.L., Spencer, H.G., 2012. Comparative and metaanalytic insights into life extension via dietary restriction. Aging Cell 11, 401-409. https://doi.org/10.1111/j.1474-9726.2012.00798.x 
Nakagawa, S., Poulin, R., Mengersen, K., Reinhold, K., Engqvist, L., Lagisz, M., Senior, A.M., 2015. Meta-analysis of variation: ecological and evolutionary applications and beyond. Methods Ecol. Evol. 6, 143-152. https://doi.org/10.1111/2041-210X.12309

Nakagawa, S., Santos, E.S.A., 2012. Methodological issues and advances in biological meta-analysis. Evol. Ecol. 26, 1253-1274. https://doi.org/10.1007/s10682-012-95555

Nakagawa, S., Schielzeth, H., 2013. A general and simple method for obtaining R2 from generalized linear mixed-effects models. Methods Ecol. Evol. 133-142. https://doi.org/10.1111/j.2041-210x.2012.00261.x@10.1111/(ISSN)2041210X.STATSTOO

Nakagawa, S., Schielzeth, H., 2012. The mean strikes back: mean-variance relationships and heteroscedasticity. Trends Ecol. Evol. 27, 474-475.

https://doi.org/10.1016/j.tree.2012.04.003

Noble, D.W.A., Lagisz, M., O'dea, R.E., Nakagawa, S., 2017. Nonindependence and sensitivity analyses in ecological and evolutionary meta-analyses. Mol. Ecol. 26, 2410-2425. https://doi.org/10.1111/mec.14031

O’Dea, R.E., Lagisz, M., Hendry, A.P., Nakagawa, S., 2019. Developmental temperature affects phenotypic means and variability: A meta-analysis of fish data. Fish Fish. 20, 1005-1022. https://doi.org/10.1111/faf.12394

O’Dea, R.E., Lagisz, M., Jennions, M.D., Nakagawa, S., 2018. Gender differences in individual variation in academic grades fail to fit expected patterns for STEM. Nat. Commun. 9, 1-8. https://doi.org/10.1038/s41467-018-06292-0

Paradis, E., Schliep, K., 2019. ape 5.0: an environment for modern phylogenetics and evolutionary analyses in R. Bioinformatics $35,526-528$. https://doi.org/10.1093/bioinformatics/bty633

R Core Team, 2018. R: A language and environment for statistical computing. R Foundation for Statistical Computing, Vienna, Austria.

Réale, D., Dingemanse, N.J., Kazem, A.J.N., Wright, J., 2010. Evolutionary and ecological approaches to the study of personality. Philos. Trans. R. Soc. B Biol. Sci. 365, 39373946. https://doi.org/10.1098/rstb.2010.0222

Réale, D., Reader, S.M., Sol, D., McDougall, P.T., Dingemanse, N.J., 2007. Integrating animal temperament within ecology and evolution. Biol. Rev. 82, 291-318. https://doi.org/10.1111/j.1469-185X.2007.00010.x

Rees, J., Cranston, K., 2017. Automated assembly of a reference taxonomy for phylogenetic data synthesis. Biodivers. Data J. 5, e12581. https://doi.org/10.3897/BDJ.5.e12581

Reinhold, K., Engqvist, L., 2013. The Variability Is in the Sex Chromosomes. Evolution 67, 3662-3668. https://doi.org/10.1111/evo.12224 
Rothstein, H.R., Sutton, A.J., Borenstein, M., 2005. Publication Bias in Meta-Analysis:

Prevention, Assessment and Adjustments. John Wiley \& Sons, Ltd. https://doi.org/10.1002/0470870168.ch1

Rowiński, P.K., Rogell, B., 2017. Environmental stress correlates with increases in both genetic and residual variances: A meta-analysis of animal studies. Evolution 71, 1339-1351. https://doi.org/10.1111/evo.13201

Sánchez-Tójar, A., Moran, N.P., O’Dea, R.E., Reinhold, K., Nakagawa, S., 2019. Materials for "lllustrating the importance of meta-analysing variances alongside means in ecology and evolution." Open Sci. Framew. https://doi.org/10.17605/OSF.IO/YJUA8

Sánchez-Tójar, A., Nakagawa, S., Sánchez-Fortún, M., Martin, D.A., Ramani, S., Girndt, A., Bókony, V., Kempenaers, B., Liker, A., Westneat, D.F., Burke, T., Schroeder, J., 2018. Meta-analysis challenges a textbook example of status signalling and demonstrates publication bias. eLife 7, e37385. https://doi.org/10.7554/eLife.37385

Senior, A.M., Gosby, A.K., Lu, J., Simpson, S.J., Raubenheimer, D., 2016. Meta-analysis of variance: an illustration comparing the effects of two dietary interventions on variability in weight. Evol. Med. Public Health 2016, 244-255. https://doi.org/10.1093/emph/eow020

Senior, A.M., Nakagawa, S., Lihoreau, M., Simpson, S.J., Raubenheimer, D., 2015. An Overlooked Consequence of Dietary Mixing: A Varied Diet Reduces Interindividual Variance in Fitness. Am. Nat. 186, 649-659. https://doi.org/10.1086/683182

Senior, A.M., Nakagawa, S., Raubenheimer, D., Simpson, S.J., Noble, D.W.A., 2017. Dietary restriction increases variability in longevity. Biol. Lett. 13, 20170057. https://doi.org/10.1098/rsbl.2017.0057

Senior, A.M., Viechtbauer, W., Nakagawa, S., 2020. Revisiting and expanding the metaanalysis of variation: The log coefficient of variation ratio, InCVR. bioRxiv. https://doi.org/10.1101/2020.01.06.896522

Senior, A.M., Viechtbauer, W., Nakagawa, S., in preparation. Revisiting and expanding meta-analysis of variation: the log coefficient of variation ratio, InCVR.

Simons, M.J.P., 2015. Questioning causal involvement of telomeres in aging. Ageing Res. Rev. 24, 191-196. https://doi.org/10.1016/j.arr.2015.08.002

Stewart, G., 2009. Meta-analysis in applied ecology. Biol. Lett. 6, 78-81. https://doi.org/10.1098/rsbl.2009.0546

Tschirren, B., Rutstein, A.N., Postma, E., Mariette, M., Griffith, S.C., 2009. Short- and longterm consequences of early developmental conditions: a case study on wild and domesticated zebra finches: Life-history strategies of wild and domestic birds. J. Evol. Biol. 22, 387-395. https://doi.org/10.1111/j.1420-9101.2008.01656.x 
Viechtbauer, W., 2010. Conducting Meta-Analyses in R with the metafor Package. J. Stat. Softw. 36, 1-48. https://doi.org/10.18637/jss.v036.i03

Walsh, B., Lynch, M., 2018. Evolution and Selection of Quantitative Traits. Oxford University Press, New York, NY, USA.

Wickham, H., 2016. ggplot2: Elegant Graphics for Data Analysis, 2nd ed, Use R! Springer International Publishing. 